\title{
Recycling Jorf Lasfar fly ash as an additive to cement
}

\author{
K Nabih*, A Quaboul, A Hamadi. \\ Labortory of solid state chemistry \\ Department of chemistry, Faculty of Sciences, B.P.1014, Rabat, Morocco. \\ *Khadijanabih@Yahoo.fr
}

\begin{abstract}
Recycling fly ash is a good example of valorization of waste. It gives a solution the environmental problem by avoiding land filling, and reducing $\mathrm{CO} 2$ emission in the atmosphere. In this work we studied the physical-chemical characteristics of Jorf Lasfar fly ash. The parameters investigated were particle size, density, specific surface Blaine, chemical and mineralogical compositions. The techniques used are scanning electronic microscope (SEM), transmission electronic microscope (TEM), X-rays fluorescence (XRF), X-rays diffraction (XRD) and atomic spectrometry emission coupled with inductive plasma ICP. We also conducted a study on the mechanical behavior of type CPJ45 cements produced from a combined grinding of clinker, limestone and gypsum. The substitution of a portion of the clinker by different percentages of fly ash was conducted. We noticed that the compression and bending resistances for these mixtures went through a maximum at 28 days with the addition of $7 \%$ (by mass) of ash. This result showed that the mineral and chemical compositions of this ash conferred a Pozzoulanic power to the cement studied.
\end{abstract}

\section{Introduction}

The implementation of concrete Portland is the basis of progress in the field of construction since the early 20th century. Witch made of Portland cement the most universally used material..This artificial material results from the combination of raw materials composed of limestone, clay, shale and iron ore. After being crushed, the mixture is then baked in a rotary kiln at a maximum mixture is then baked in a rotary kiln at a maximum temperature of $1450^{\circ} \mathrm{C}$ to form the clinker. The latter is grounded with other additives (limestone, gypsum, fly ash etc ...) to give a final product called cement.

The quality of raw materials and clinker is the major element that provides good quality cement. Demand for concrete, due to the need for infrastructure in various countries worldwide will increase significantly in coming years; the result is the emission of huge amounts of $\mathrm{CO}_{2}$ into the atmosphere [1].In recent years, cement producers were interested in incorporating some of the Portland cement industry by-products, likely to develop hydraulic properties. Recycling these by-products in building materials is a good example of waste recovery. It allows to improve the heat balance in an area of high energy consumption, solve the environmental problem related to the storage form of dumps or dumping at sea of industrial by-products such as fly ash, phosphogypsum [2] It also solve the problem of the emission of $\mathrm{CO}_{2}$ into the atmosphere [1].

The universal use of cements containing additions allowed us to undertake a systematic and fundamental investigation of the effect of Jorf Lasfar fly ash on physical chemical proprieties of cement $\mathrm{CPJ}_{45}$ that contains limestone filler.

During the past decade, many researchers have focused on the utilization of small particle sizes fly ash with low carbon content as an additive to cement. Fly ash with these characteristics contributes to the development of mechanical strength in the short and long term of concrete, promote resistance to sulphate attack and reduce the heat of hydration. It allows also reducing the consumption of career materials and air pollution. By using less Portland clinker. 


\section{Experimental}

In this study fly ash and clinker were taken respectively from the storage and the output of cement kiln at Asment plant ( groupe CIMPOR). The gypsum was dried at $110^{\circ} \mathrm{C}$ and limestone filler at $40^{\circ} \mathrm{C}$ in an oven for 24 hours. Three kilogram's of cement were prepared by grinding in a ball mill with different constituents (clinker, gypsum, and limestone filler) by variable compositions. Fly ash is added at the end of each grinding. CPJ cement type 45 on which we conducted our study were made according to standard Moroccan NM10.01.004 [3 ]. The composition and mass were of the order of $71.2 \%$ clinker, $20 \%$ limestone and $3.8 \%$ gypsum.

Mineralogical composition of the ash was determined by X-rays diffraction, using a Philips X'Pert Pro diffract meter. Chemical composition was evaluated by X-rays fluorescence (XRF) Philips PW 1660 spectrometer. The percentages of the elements were given by the transmission electron microscope TEM Tecnai $\mathrm{G}^{2}$ series type. The morphology and distribution of the particles were examined by scanning electron microscopy (SEM) Quanta TM Series. The levels of trace elements were analyzed by spectrometry Atomic emission Jobin Yvan Ultima 2 type coupled to inductive plasma. These techniques were performed in the National Center for Scientific and Technological Research (CNRST, Rabat). The particle size was investigated using an alpine sieve ranging from 45 to 100 micron. The surface area was determined by Blaine and density by pycnometer method. The amount of free lime in Asment clinker was estimated using the ethylene glycol method

\section{Results}

\subsubsection{Analysis by $X$-ray fluorescence $(X R F)$}

The chemical composition of Asment clinker, limestone filler and fly ash were carried out. The result from Xray fluorescence spectrometer) Shows that Jorf Lasfer fly ash is rich in silica and alumina, and contains a low percentage of $\mathrm{CaO}$, wich allows us to consider that the this ash belongs to the class $\mathrm{F}$. Bogue formulas [4] was used to compute the mineralogical composition of the clinker. The result is given in Table III.2. The same analysis shows that the gypsum contains $20 \%$ of impurity and the mass of $\mathrm{SO}_{3}$ is about $31.75 \%$.

\subsubsection{Analysis by $X$-ray diffraction (XRD)}

The X-ray diffraction performed on our fly ash (Figures 3.1.1 and 3.1.2) highlight different crystalline phases determined using the software "X Powder. After removal of background noise, the spectrum of X-ray diffraction shows the presence of these phases and their weight percentages. We comply with the mullite $\left(\mathrm{Al}_{6} \mathrm{Si}_{2} \mathrm{O}_{13}\right)$ which is $63.2 \%$, quartz $\left(\mathrm{SiO}_{2}\right)$ of $31.3 \%$, magnetite $\left(\mathrm{Fe}_{3} \mathrm{O}_{4}\right)$ of $4 \%$ and hematite $\left(\mathrm{Fe}_{2} \mathrm{O}_{3}\right) 1.6 \%$. We note that our ash contains a large percentage of quartz and mullite, which gives it a good pouzzolanic power. We also observe the existence of a halo that has a maximum in the vicinity of $2 \theta=23^{\circ}$, due to the presence of an amorphous reactive glass phase [5].

\subsubsection{Analysis by scanning electron microscopy (SEM)}

Scanning electron microscopy was used to study the morphology of fly ash Jorf Lasfar. The photos (1-6) show that our ash is in the form of a powder consisting essentially of fine spherical particles whose dimensions are between 0.5 and 150 microns. We also observe the existence of different shapes. In general, the grain surface is smooth, shiny and covered by very small spherical grains.

\subsubsection{Analysis by transmission electron microscopy (TEM)}

Analysis by electron microscope transmission showed that Jorf Lasfar fly ash is rich in silicon and aluminum. We also note the presence of minor elements such as: potassium, magnesium, titanium, calcium and iron. Other elements exist in trace amounts as sodium, sulfur, vanadium, manganese and phosphorus.

The analysis performed on several grains of ashes of various sizes and shapes showed that their compositions differ from one grain to another depending on the size and composition, of each particle (photo 7.). Each particle is an isolated system which does not interact with its neighbors [6-8].The percentages by weight and the ash analyzed spectra are shown in figure 3.1.4.et Table 3.1.4. Considering the shape and composition of grain given by the transmission electron microscope TEM (Fig.3.1.4). We can say that this grain is the as mullite according to L. Ly, E. R. Vance and al, mullite has a spherical shape [9]. 
Table 3.1.1: Compositions of clinker, limestone and fly ash (wt\%) given by XRF

\begin{tabular}{|c|l|l|l|}
\hline Oxides & Clinker & limestone & Fly ash \\
\hline $\mathrm{SiO}_{2}$ & 20.91 & 14.06 & 56.03 \\
\hline $\mathrm{Al}_{2} \mathrm{O}_{3}$ & 5.14 & 1.32 & 25.05 \\
\hline $\mathrm{Fe}_{2} \mathrm{O}_{3}$ & 3.77 & 2.41 & 6.91 \\
\hline $\mathrm{CaO}$ & 64.58 & 44.92 & 1.42 \\
\hline $\mathrm{MgO}$ & 1.64 & 0.42 & 0.97 \\
\hline $\mathrm{SO}_{3}$ & 1.56 & 0 & 0.42 \\
\hline $\mathrm{K}_{2} \mathrm{O}$ & 0.83 & 0.22 & 2.42 \\
\hline $\mathrm{TiO}_{2}$ & 0.38 & 0.27 & 1.52 \\
\hline $\mathrm{MnO}$ & 0.08 & 0.07 & 0.07 \\
\hline $\mathrm{Na}_{2} \mathrm{O}$ & 0.37 & 0 & 0.01 \\
\hline $\mathrm{P}_{2} \mathrm{O}_{5}$ & 0.37 & 0.46 & 0.10 \\
\hline $\mathrm{CaO}_{\text {libre }}$ & 1.40 & - & - \\
\hline
\end{tabular}

Table 3-1.2: Industrial mineral composition of clinker (wt $\%$ )

\begin{tabular}{|c|c|c|c|}
\hline $\mathbf{C}_{\mathbf{3}} \mathbf{S}$ & $\mathbf{C}_{\mathbf{2}} \mathbf{S}$ & $\mathbf{C}_{\mathbf{3}} \mathbf{A}$ & $\mathbf{C}_{\mathbf{4}} \mathbf{A F}$ \\
\hline 53.46 & 19.70 & 7.25 & 11.46 \\
\hline
\end{tabular}
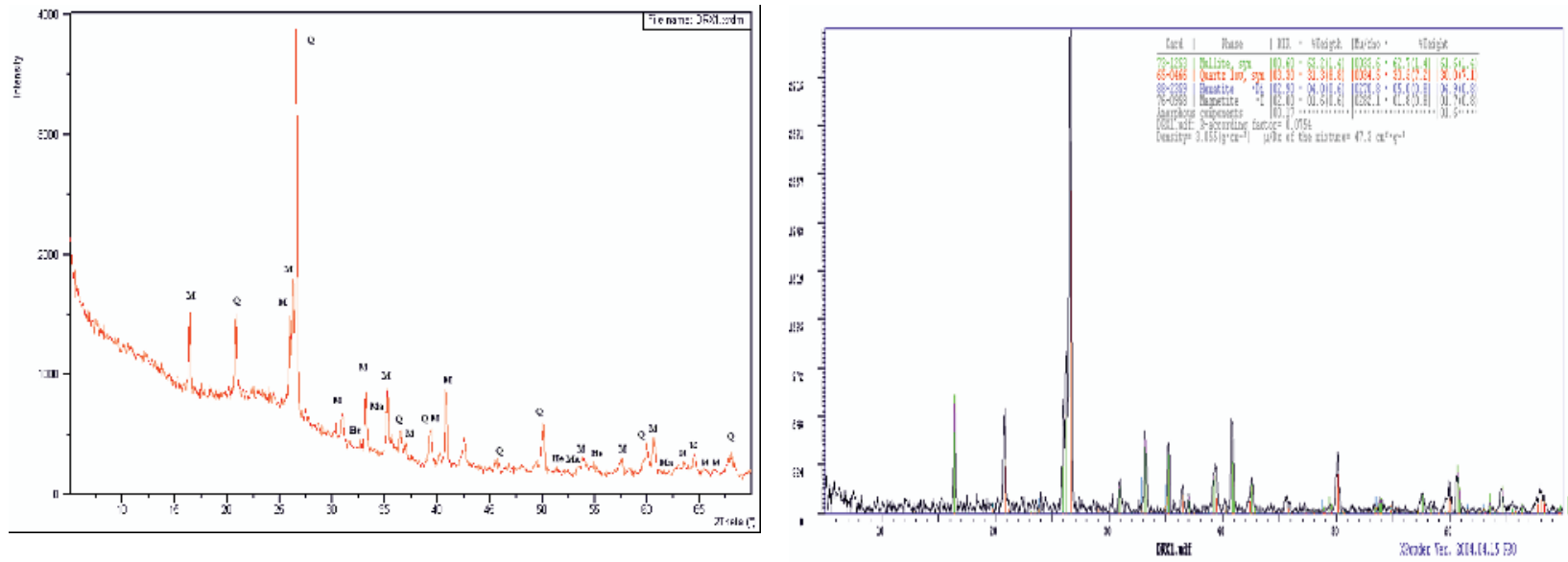

Figures. 3.1.1 et 3.12: Spectrum of X-ray diffraction of fly ash with the processed by the software "X Powder"

Analysis by atomic emission spectrometry coupled to the ICP (Inductively Coupled Plasma) of the ash samples allowed us to identify all trace elements and to determine their concentration(Table 3.1.5. $\mathrm{Ba}, \mathrm{Ni}, \mathrm{Li}$ and $\mathrm{V}$ in high concentration have a beneficial effect on improving the mechanical hydraulic properties of the cement. These elements are found in significant amounts in our samples. We also note a high content of $\mathrm{Cr}$ which has a good effect on the color and of increasing resistance with the age [10]. Table 3.1.6 shows these elements and their contents:

\subsubsection{Particle size and surface area of fly ash}

Particle size of fly ash was investigated by using an Alpine sieve ranging from 45 to 100 microns. The surface area is determined by the method of Blaine and density measured by pycnometer method.. The result shows that our fly ash is very fine and has a very large surface area $\left(2370 \mathrm{~cm}^{2} / \mathrm{g}\right)$. and a density equal to $2,14 \mathrm{~g} / \mathrm{cm}^{3}$. The percentage of the particles sieved are 20,9\%> $80 \mathrm{um}, 28,2 \%>63 \mathrm{um}$ and 33,4> 45um. According to Lane and Best [11], fly ash class F contains many particles with size below 45 microns that can likely increase the mechanical properties of cement. We note also that the specific surface of the same ash is considerably large. This is very important for the runoff because the fineness of cement is an important feature. Other authors have confirmed that the higher the fineness of grind, the greater the rate of hydration reactions and the higher will be the mechanical strength of concrete at an early age [12]. 

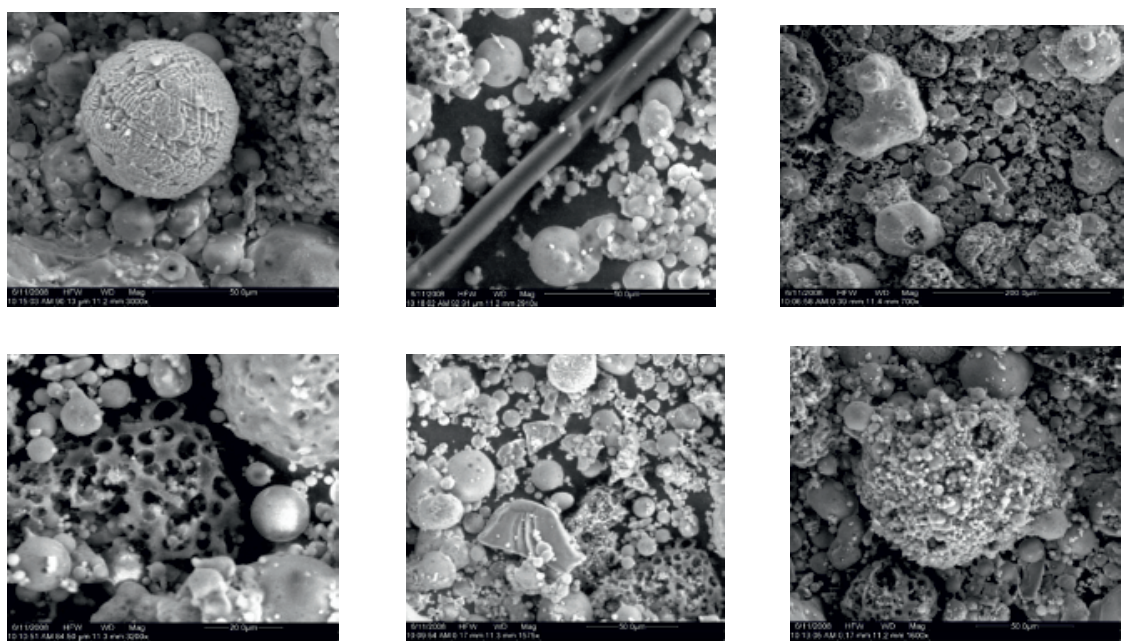

Fig.3.1.3. SEM photos (1-6) off Jorf Lasfer fly ash

Table 3.1.4: Analysis of a particle of photo7 given by TEM

\begin{tabular}{|c|l|l|}
\hline Element & Weight\% & Atomic \% \\
\hline O K & 40.5 & 55.5 \\
\hline $\mathrm{NaK}$ & 0.7 & 0.6 \\
\hline $\mathrm{MgK}$ & 1.2 & 1.1 \\
\hline $\mathrm{AlK}$ & 21.7 & 17.6 \\
\hline $\mathrm{SiK}$ & 26.4 & 20.6 \\
\hline $\mathrm{P} \mathrm{K}$ & 0.4 & 0.3 \\
\hline $\mathrm{S} \mathrm{K}$ & 0.2 & 0.32 \\
\hline $\mathrm{K} \mathrm{K}$ & 2,3 & 1 \\
\hline $\mathrm{CaK}$ & 0.9 & 0.5 \\
\hline $\mathrm{Ti} \mathrm{K}$ & 1.2 & 0.5 \\
\hline MnK & 0.1 & 0.0 \\
\hline FeK & 4.3 & 1.7 \\
\hline Total & 100.0 & 100.0 \\
\hline & &
\end{tabular}

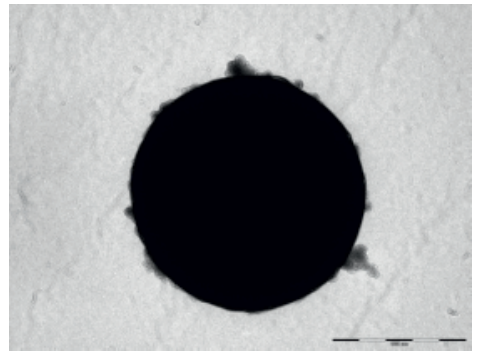

Fig.3.1.4. Photo7 and spectrum of a spherical particle of Jorf Lasfar fly ash given by TEM

\subsubsection{Substitution of clinker with fly ash}

A series of cement were prepared by grinding the clinker with varying amounts of fly ash from 3 to 10 (\% by mass). We noted that the addition of various percentages of fly ash to cement has increased the sieve 80 microns without changing the standards off refusal set initially (Table 3.2.1).

\section{Resistance to compression and bending:}

The study of mechanical properties was carried out according to standard Moroccan NM10.01.004, by determining the flexural and compressive strength of different types of cement (CPJ45). Mortars (samples of dimension $4 \times 4 \times 16 \mathrm{~cm}^{3}$ ) were prepared by mixing one part of cement with three parts of standard sand $(97 \%$ silica). The water / cement ratio (E / C) was equal to 0.5.Table 3.2.2 summarizes the results of tests which represent the evolution of mechanical properties of cement type CPJ45 as a function of fly ash percentages and time.

In the case of cement mortars type CPJ45 obtained by substitution of fly ash to clinker, we observed that the resistance to compression and bending pass through a maximum at 28 days for a percentage of fly ash $7 \%$ (by mass). Beyond this percentage, the compressive strength and bending strength showed a small decrease. With the addition of $10 \%$ fly ash the cement obtained stayed of very good quality 
Table 3.1.5 Analysis by atomic emission spectrometry coupled to ICP fly ash Jorf Lasfer

\begin{tabular}{|c|c|}
\hline Elements & CC en ppm \\
\hline$C d$ & 0.194 \\
\hline$C o$ & 54.582 \\
\hline$C r$ & 92.711 \\
\hline$C u$ & 108.195 \\
\hline $\mathrm{Mn}$ & 107.034 \\
\hline$N i$ & 141.099 \\
\hline$P b$ & 45.678 \\
\hline$S r$ & 313.167 \\
\hline$Z n$ & 96.063 \\
\hline$B a$ & 380.523 \\
\hline$V$ & 188.713 \\
\hline$L i$ & 135.680 \\
\hline
\end{tabular}

Table 3.2.1: The composition of the various cements with their refusal to $80 \mu \mathrm{m}$.

\begin{tabular}{|l|l|c|l|c|c|}
\hline Ciment & $\begin{array}{l}\text { Clinker } \\
(\mathbf{w t} \%)\end{array}$ & $\begin{array}{l}\text { (wt\%)Filler } \\
\text { limestone }\end{array}$ & $\begin{array}{l}\text { Gypsum } \\
(\% \mathbf{w t})\end{array}$ & fly ash (wt\%) & Refusal 80 $\boldsymbol{\mu m}$ \\
\hline $\mathrm{CPJ} 45$ & 76.2 & 20 & 3.8 & 0 & 2.5 \\
\hline $\mathrm{CPJ}_{3}(45)$ & 73.2 & 20 & 3.8 & 3 & 2.8 \\
\hline $\mathrm{CPJ}_{5}(45)$ & 71.2 & 20 & 3.8 & 5 & 3.3 \\
\hline $\mathrm{CPJ}_{7}(45)$ & 69.2 & 20 & 3.8 & 7 & 3.3 \\
\hline $\mathrm{CPJ}_{10}(45)$ & 66.2 & 20 & 3.8 & 10 & 3.5 \\
\hline
\end{tabular}

Table 3.2.2: Changes in mechanical properties of cement with additions of fly ash as a function of time ( 2,7 and 28 days)

\begin{tabular}{|c|c|c|c|c|c|c|}
\hline \multirow{2}{*}{ Ciments } & \multicolumn{3}{|c|}{ Compressive Strength } & \multicolumn{3}{|c|}{ Bendig Strength } \\
\hline & $2 d$ & $7 d$ & $28 d$ & $2 d$ & $7 d$ & 28d \\
\hline CPJ45 & 20,2 & 32,1 & 44,4 & 4.2 & 5.9 & 7.6 \\
\hline $\mathrm{CPJ}_{3}(45)$ & 19,2 & 30,3 & 42,3 & 4.0 & 5.5 & 7.3 \\
\hline $\mathrm{CPJ}_{5}(45)$ & 19,7 & 30,8 & 43 & 4.3 & 5.6 & 7.4 \\
\hline $\mathrm{CPJ}_{7}(45)$ & 20,8 & 31 & 43,4 & 4.4 & 5.8 & 7.6 \\
\hline $\mathrm{CPJ}_{10}(45)$ & 18,6 & 29,5 & 42,8 & 4.1 & 5.3 & 7.4 \\
\hline
\end{tabular}

\subsubsection{Addition of fly ash to cement}

In order to determine the best use of fly ash in cement production, we prepared a second set of cement by adding different proportion of fly ash to cement CPJ45. The composition (by mass) was the order of $75.3 \%$ clinker, $3.7 \%$ gypsum and $21.6 \%$ limestone. The cement was taken directly from the mill outlet. Fly ash added percentage was of the order of 3,5,7 and $10 \%$.

The study of mechanical properties was carried out according to standard Moroccan NM10.01.004, by determining the flexural and compressive strength of different types of cement (CPJ45). Mortars (samples of dimension $4 \times 4 \times 16 \mathrm{~cm}^{3}$ ) were prepared by the same way mentioned above. Table 3.31 and 3.3.2 summarize respectively the results of the composition of vatious cements with their refusal to 80um and the evolution of flexural strength of cement obtained by substituting fly ash to cement.

Table 3.3.1 The composition of various cements with their refusal to $80 \mu \mathrm{m}$.

\begin{tabular}{|c|c|c|c|}
\hline Types of cement & Cement (wt \%) & Fly ash(wt\%) & Refusal to 80 $\boldsymbol{\mu m}(\mathbf{w t} \%)$ \\
\hline $\mathrm{CPJ}_{4} 4$ & 100 & 0 & 1.8 \\
\hline $\mathrm{CPJ}_{3}(45)$ & 97 & 3 & 2.0 \\
\hline $\mathrm{CPJ}_{5}(45)$ & 95 & 5 & 2.6 \\
\hline $\mathrm{CPJ}_{7}(45)$ & 93 & 7 & 2.8 \\
\hline $\mathrm{CPJ}_{10}(45)$ & 90 & 10 & 3.3 \\
\hline
\end{tabular}


Table 3.3.2: Evolution of the flexural strength of cements obtained by substitution of fly ash to clinker

\begin{tabular}{|l|l|l|l|l|l|l|}
\hline \multirow{2}{*}{ Cement } & \multicolumn{4}{|c|}{ Compressive Strength } & \multicolumn{3}{|c|}{ Bendig Strength } \\
\cline { 2 - 7 } & $\mathbf{2 j}$ & $\mathbf{7 j}$ & $\mathbf{2 8 j}$ & $\mathbf{2 j}$ & $\mathbf{7 j}$ & $\mathbf{2 8 j}$ \\
\hline $\mathrm{CPJ} 45$ & 17.5 & 27.9 & 39.5 & 3.8 & 5.3 & 6.9 \\
\hline $\mathrm{CPJ}_{3}(45)$ & 17.6 & 27.3 & 40.6 & 3.9 & 5.4 & 7.4 \\
\hline $\mathrm{CPJ}_{5}(45)$ & 18.2 & 27.8 & 41.1 & 4.0 & 5.5 & 7.5 \\
\hline $\mathrm{CPJ}_{7}(45)$ & 19.3 & 28.9 & 41.8 & 4.1 & 5.6 & 7.7 \\
\hline $\mathbf{C P J}_{\mathbf{1 0}}(\mathbf{4 5})$ & 17.9 & 27.0 & 39.0 & 3.7 & 5.3 & 7.3 \\
\hline
\end{tabular}

\section{Conclusions}

The physico-chemical characterization of Jorf Lasfar fly ash was determined by different techniques. SEM analysis showed that the microstructures of the ash are usually in the form of fine particles of different shapes, generally smooth spherical shape their dimensions are included between 0.5 and 150 microns. From. X-RD study we had noticed the existence quartz, mullite, Hematite and magnetite. As crystalline phases We also noted the presence of reactive amorphous phase. The chemical composition of the same ash was given by XRF. It shows that the ash belongs to class $\mathrm{F}$ because of its low $\mathrm{CaO}$ composition. TEM has inquired that the ash mineral matter is composed mainly of silicon and aluminum and other minor elements. Atomic emission spectrometry coupled with linkage Inductive Plasma allowed us to identify the trace elements and determine their contents. These elements have many influences on the cooking process and the performance of the cement.

The substitution of a portion of the clinker by different percentages of fly ash was conducted. The result showed that compression and bending resistances went through a maximum of $7 \%$ (by mass) at 28 days. The addition of fly ash to Portland cement increased the mechanical resistance for the same period. This is due to the mineralogical and chemical composition of the ash studied which exhibit specific properties of finesse, and good hydraulic and Pouzzolanic activity.

\section{Acknowledgement}

To Asment Temara Plant (CIMPOR) for supporting this study trough the use of their laboratory facilities. To UATRS - CNRST (Unité d'Appui à la Recherché Scientifique- Centre National de la Recherché Scientifique et Technique) Rabat, Morocco

\section{References}

1. Malhotra V. M., “ Role of Supplementary Cementing Materials in Reducing Greenhouse Gas Emissions”, MTL Division Report MTL 98-03, Natural Resources Canada, Ottawa,p.17 (1998)

2. Bastide J. C.,. La fabrication de ciment français”, Edition Eyrolles, Paris, p.61(1993).

3. Norme Marocaine, Liants hudrauliques, NM10.01.004, Novembre (1985).

4. Bogue R. H., La chimie des ciments Portland, Edition Eyrolles, Paris(1952)

5. Diamond S, On the glass Present in low calcium and high calcium fly ashes, Cement and Concrete Research, 13, 459-464(1983)

6. Eyrolles, A. Jarrige.. Les Cendres Volantes - Propriétés - Applications Industrielles. (1971)

7. Ravina D.,. Production and collection of fly ash for use in concrete, Int. proceeding symposium of Fly Ash Incorporation in hydrated cement systems, Edited by S. Diamond, Materials Research Society, Boston, MA, p. 2-11 (1981).

8. Torrey S,. Collection ash utilisation - Fly ash - Bottom as hand slag, Pollution Technology review, Noyes Data corporation, New Jerey, $\mathrm{N}^{\circ} 48$. (1978)

9. Vance L. Ly, E. Perera R., Aly and D. S., Olufson Z. KLeaching of Geopolymers in Deionised Water, vol. 3. (2007).

10. La composition chimique du clinker, Chap.III, www.scaek.dz/docs_techniques/chimie

11. Lane, R. O, and Best J. F. Properties of fly ash in portland cement concrete, Concrete International.(1982) 